\title{
Factors Associated with Perceived Stress of Parents with Children and Teenagers Suffering From Cerebral Palsy
}

\author{
Mustapha Mouilly ${ }^{1,2}$, Noureddine Faiz ${ }^{1,3}$, Ahmed Omar Tohami Ahami ${ }^{1}$ \\ ${ }^{I}$ Department of Biology, Neurosciences and Nutritional Health/ Ibn Tofail University, Morocco \\ ${ }^{2}$ Mohammed Diouri Health Center, Kenitra, Morocco \\ ${ }^{3}$ SMBA Health Center, Mohammadia, Morocco
}

\begin{abstract}
All individuals are vulnerable to stress, to varying degrees, and each has a potential for it to increase its competence to deal with it. Parents of children with cerebral palsy through difficult periods in their lives, resulting in a disturbed mental health, expressed a high level of stress. Rare are the studies which launch out to study the impact of the disease on the mental state of the parents and identify factors associated with the development of perceived stress in this population. A descriptive cross-sectional study was conducted among a sample of 67 relatives (34 mothers and 33 fathers) of children with cerebral palsy. Scales and questionnaires were used with the aim to identify the level of perceived stress of parents with children and adolescents suffering from cerebral palsy compared between mothers and fathers and to determine the factors associated with perceived stress among parents. Most of our results support our hypothesis and confirms the data of the literature in a field little studied in Morocco. Indeed it seems that the parents of children and adolescents with cerebral palsy suffer from high levels of stress, suffering seems more pronounced in mothers than in fathers whose partners are factors related to gender (female), marital status (divorce) and the socio-economic level (law). The sample size is small and the comparison group is absent. Similar research would be interesting if it would cover a wider range in order to extrapolate results and develop a coping strategy of adaptation and support. We should find the solutions helping families to overcome this deteriorated experience and break their isolation to reduce their stress and improve their conjugal balance.
\end{abstract}

Keywords: cerebral palsy, parents, perceived stress.

\section{Introduction}

The Cerebral palsy (CP) is a group of disorders of the development of movement and posture causing activity limitations that are attributed to non-progressive disturbances that occur in the developing fetal or infant brain. Cerebral palsy movement disorders are often accompanied by sensitive damage, sensory, communication, prehensions and / or behavior ${ }^{[1]}$. The management of children with chronic illness has gradually shifted from the hospital to the home where care and monitoring taking responsibilities primarily rest on the shoulders of the family. This is why researchers have started to investigate the child's family background with a chronic disease ${ }^{[2]}$. Particularly perceived stress was successively conceptualized as a non-specific response of the body to aggression and as a multifactorial process with cognitive, emotional, behavioral and neuro-hormonal, in close interaction with each other ${ }^{[3]}$. The parents lived opposite to the cerebral palsy from which their child suffers has been little studied. Thus, knowledge of the perceived level of stress experienced by parents and factors associated with emotional disorder remain unknown. For this reason the objectives of our global study, exploratory, are: (1) identify the level of perceived stress of parents with children and adolescents suffering from $\mathrm{CP}$ compared between mothers and fathers ; (2) determine the factors associated with perceived stress in parents with children and adolescents suffering from CP. The hypotheses postulate that (i) Parents with cerebral palsied child suffer from a high level of perceived stress and the factors associated with this level of stress are related to socio-economic and psychological support.

\subsection{Subjects}

\section{Methodology}

All parents were recruited through the Moroccan Association for Better Life which manages the Early Medical Social Action Center in Kenitra, Morocco (CAMSP) and the rehabilitation center for handicapped children. The inclusion criteria were: to have a child aged between 2 and 17 years and know the diagnosis for minimum 1 year. The total sample consisted of 67 parents of children suffering from CP. It breaks down as follows: 33 fathers and 34 mothers. 


\subsection{Measuring instruments}

\subsubsection{Questionnaire of demographic information}

The questionnaire contains some relevant information for research and analysis of results for children with CP such as gender, age, rank in sibling group, diagnosis, age, rehabilitation, associated disorders and autonomy. Parental status was described by the following: gender, age, marital status, socioeconomic status, occupation and number of children.

\subsubsection{Perceived stress scale (PSS; Cohen, 1983)}

PSS measuring stress in general and not specifically. This scale assesses the importance with which life situations are perceived as threatening, unpredictable, uncontrollable and painful. ${ }^{[4]}$

\subsubsection{Questionnaire of social perceived support (QSSP)}

The scale of perceived social support is used to assess the type of perceived support, the resources of this support, the number of people who provide it (or availability) and perceived quality (or satisfaction). It consists of four questions reflecting the main forms of social support: esteem support (comfort, listening in difficult times), material or financial support (direct assistance when necessary), the informational support (advice or suggestions from others). The emotional support (reassure, restore confidence) for each type of support, it helps to know how many people providing it, who are these people (family, friends, colleagues, specialists ...) and if the subject is satisfied with this support. So we get two scores for each subject: availability (number of persons involved in the support) and perceived satisfaction (quality of that support). This tool also provides information about the nature of social support perceived by the person. ${ }^{[5]}$.

\subsection{Statistical analyses}

All statistical analyzes were performed using the statistical package for social sciences (SPSS, version 20.0). The normality of the variables distribution was tested by the Kolmogorov-Smirnov test. The normally distributed variables are shown as mean \pm standard deviation, and those distributed abnormally are shown as median (interquartile range 25 to $75 \%$ ). The homogeneity of variance was tested using Levene's test, and Welch's correction was used in the case of heterogeneous variances. ANOVA or the Mann-Whitney tests were performed to test the significance between independent samples. The chi-square test or Fisher's exact test were used to test the independence between categorical variables. The associated factors were determined by linear regression univariate and multivariate analyzes. Only p values less than $30 \%$ were included in the multivariate model. $\mathrm{P}$ values less than 0.05 were considered statistically significant.

\section{Results}

On the whole, 67 parents whose 34 mothers $(50.7 \%)$ and 33 fathers $(49.3 \%)$ participated in the study, the average age of parents is about $(43.0 \pm 8.5)$. The most were in couples $n=66(98.5 \%)$ and a divorced mother (1.5\%), $16.4 \%$ of the population has one child. The majority of mothers believe that they support the heavy load, while $(11.8 \%)$ believe that family responsibilities are equitably distributed. $55(82.1 \%)$ of parents believe that the care of their child is weak and in need of social support, Or $12(17.9 \%)$ are satisfied with their care. 65 (97\%) of children are not autonomous and depend on adults for all activities of daily living, 2 (3.0\%) are autonomous, but all children present disorders associated with their motor disability. Table I From the results shown in Table II, perceived stress was significantly higher among mothers of children and adolescents with CP than father's $(p<0.001)$. A statistically significant difference was recorded between the availability of maternal satisfaction score and fathers of cerebral palsied teenagers, less good for mothers. $(p<0.05)$, however, there is no difference in parental satisfaction score of CP children $(\mathrm{p}=0.068)$. Table III

The multivariate analyzes are intended to check the following exploratory question: what are the factors associated with disturbance of mental health of mothers and fathers with cerebral palsied children and teenagers. In multivariate analysis after adjustment for age, sex, marital status, socioeconomic level, occupation, number of children, the sex of the child, the child's autonomy, the esteem support satisfaction, material support satisfaction, informational support satisfaction, emotional support satisfaction and the availability satisfaction only sex, marital status and socioeconomic status are associated with stress perceived as risk factors for parents of children and teenagers suffering from CP; that is mothers are predisposed to have a high stress level seven times if they have a child with $\mathrm{CP}$, and divorced tend to have a level of perceived stress twelve times higher than among married, especially stress level is very high among families whose socio economic level is low. Table IV 
Table I. Descriptive statistics of the studied population $(\mathrm{n}=67)$

\begin{tabular}{|c|c|}
\hline Characteristic & Value $(\mathrm{N}=67)$ \\
\hline Age (in year) 1 & $43 \pm 8,5$ \\
\hline \multicolumn{2}{|l|}{ Parents 2} \\
\hline Fathers & $33(49,3)$ \\
\hline Mothers & $34(50,7)$ \\
\hline \multicolumn{2}{|l|}{ Marital status 2} \\
\hline Divorced & $66(98,5)$ \\
\hline Couple & $1(1,5)$ \\
\hline \multicolumn{2}{|l|}{ Socio-economic level 2} \\
\hline Bottoms $(<200$ Euros $)$ & $19(28,4)$ \\
\hline Average (between 200 and 500Euros) & $40(59,7)$ \\
\hline High $(>500$ Euros $)$ & $8(11,9)$ \\
\hline \multicolumn{2}{|l|}{ Profession of mothers 2} \\
\hline No occupation & $23(67,6)$ \\
\hline Workforce & $6(17,6)$ \\
\hline Middle management & $4(11,8)$ \\
\hline Senior & $1(2,9)$ \\
\hline \multicolumn{2}{|l|}{ Profession of fathers 2} \\
\hline No occupation & $0(0)$ \\
\hline Workforce & $22(66,7)$ \\
\hline Middle management & $10(30,3)$ \\
\hline Senior & $1(3,0)$ \\
\hline \multicolumn{2}{|l|}{ Autonomy of children 2} \\
\hline No & $65(97)$ \\
\hline Yes & $2(3)$ \\
\hline
\end{tabular}

1 Mean \pm Standard deviation, 2 Effectif $(\%)$

Table II. Description of the perceived Stress of the fathers and the mothers with children and teenagers suffering from $\mathrm{CP}$

\begin{tabular}{|l|l|c|c|}
\hline & Mothers $(\mathrm{n}=34)$ & Fathers $(\mathrm{n}=33)$ & $\mathrm{p}$ value1 \\
\hline Child & & & $<0,001$ \\
\hline PSS Score & $32,70( \pm 3,09)$ & $24,48( \pm 3,55)$ & $<0,001$ \\
\hline Teenager & & & $25( \pm 3.59)$ \\
\hline PSS Score & $37.55( \pm 3.80)$ & & $<$ \\
\hline
\end{tabular}

$1 \mathrm{p}$ value test $\mathrm{T}$ for independent sample

Table III. Description of the score of satisfaction of availability of the fathers and the mothers of the children and teenagers with PC

\begin{tabular}{|c|l|l|c|}
\hline & Mothers $(\mathrm{n}=34)$ & Fathers $(\mathrm{n}=33)$ & $\mathrm{p}$ value1 \\
\hline Child & & & 0,068 \\
\hline $\begin{array}{c}\text { Score of satisfaction of } \\
\text { availability }\end{array}$ & $11,22 \pm 2,69$ & $13,09 \pm 3,96$ & \\
\hline \multicolumn{1}{|c|}{ Teenager } & & & 0,004 \\
\hline ff satisfaction of availability & $10,18 \pm 1,53$ & $13,10 \pm 2,47$ & \\
\hline
\end{tabular}

$1 \mathrm{p}$-values determined with the test of ANOVA.

\section{Discussion}

The sample of this study is composed of parents (33fathers and 34mothers) of cerebral palsied children and adolescents, few studies who are interested in studying the suffering of fathers and mothers, knowing that they both represent the link low in a multidisciplinary management. The phase of adolescence is a critical period of transition. The parents in this period should be more available. The results of our study indicate that parents of children and teenagers with CP suffer from a high state of stress and disruption in their mental health, which echoes the literature ${ }^{[6,7,8,9]}$. The mother who has primary responsibility in the home suffers more than fathers, especially that our entire sample of children and adolescents is almost dependent on adults in all activities of daily living. This corroborates the literature data ${ }^{[10,9]}$, fathers seem less available, evoking their occupation. Few studies have described the experiences of parents and identified factors that influences the adaptation of parents to their disabled child ${ }^{[11,12,13,14,15]}$. Similarly, Hilbert and al., 2000; Elliot and Luker, 1997) ${ }^{[16,17]}$, showed in their studies concerning holders parents of children with chronic diseases and disabling the latter have negatively affected their family and social life that is found totally dominated by the disease. Another study showed the existence of a significant level of risk for depression and anxiety disorders particularly in the mother, others claim that mothers had higher risks than fathers. 
Table IV. Factors associated with the stress perceived of parents with children and teenagers suffering from CP in univariée and multivariate analysis

\begin{tabular}{|c|c|c|c|c|c|c|c|}
\hline $\begin{array}{c}\text { Associated } \\
\text { factors }\end{array}$ & \multicolumn{3}{|c|}{ Univariate analysis } & \multicolumn{3}{c|}{ Multivariate analysis } \\
\hline & B & IC 95 \% & p-Value & B adjusted & \multicolumn{2}{c|}{ IC 95 \% } & p-Value \\
\hline Age & $-0,091$ & {$[-0,27 ; 0,09]$} & 0,31 & \multicolumn{1}{|c|}{ Not introduced into the multivariate model } \\
\hline Sex & 9,63 & {$[7,79 ; 11,47]$} & $<0,001$ & 7,589 & {$[5,08 ; 10,1]$} & 0,000 \\
\hline S.familiale & 16,73 & {$[5,01 ; 28,44]$} & 0,006 & 12,520 & {$[5,29 ; 19,75]$} & 0,001 \\
\hline N_S_E & 1,46 & {$[-0,97 ; 3,89]$} & 0,24 & 1,734 & {$[0,13 ; 3,34]$} & 0,04 \\
\hline Profession & $-2,92$ & {$[-4,62 ;-1,22]$} & 0,001 & $-0,912$ & {$[-2,28 ; 0,46]$} & 0,19 \\
\hline Numbers of child & $-1,11$ & {$[-1,62 ; 1,4]$} & 0,89 & Not introduced into the multivariate model \\
\hline Sex of the PC & 0,87 & {$[-2,26 ; 4,01]$} & 0,58 & Not introduced into the multivariate model \\
\hline Age_PC & 0,24 & {$[-0,07 ; 0,56]$} & 0,13 & 0,128 & {$[-0,07 ; 0,32]$} & 0,19 \\
\hline Autonomy & 2,09 & {$[-6,75 ; 10,92]$} & 0,64 & Not introduced into the multivariate model \\
\hline $\begin{array}{c}\text { S. with the } \\
\text { support of regard }\end{array}$ & $-1,02$ & {$[-2,45 ; 0,4]$} & 0,16 & $-0,131$ & \multicolumn{2}{|c|}{$[-1,61 ; 1,35]$} & 0,86 \\
\hline $\begin{array}{c}\text { S. with the } \\
\text { material support }\end{array}$ & $-1,18$ & {$[-2,34 ; 0,03]$} & 0,045 & $-1,01$ & \multicolumn{2}{|c|}{$[-2,51 ; 0,5]$} & 0,86 \\
\hline $\begin{array}{c}\text { S. with the } \\
\text { informative } \\
\text { support }\end{array}$ & $-0,84$ & {$[-2,69 ; 1,01]$} & 0,37 & Not introduced into the multivariate model \\
\hline $\begin{array}{c}\text { S.with emotional } \\
\text { support }\end{array}$ & $-3,11$ & {$[-4,13 ;-2,09]$} & $<0,001$ & $-1,03$ & {$[-2,91 ; 0,85]$} & 0,28 \\
\hline $\begin{array}{c}\text { S. with the } \\
\text { availability }\end{array}$ & $-0,78$ & {$[-1,22 ;-0,35]$} & 0,001 & 0,57 & {$[-0,64 ; 1,77]$} & 0,35 \\
\hline
\end{tabular}

S.: satisfaction

In our study, the degree of satisfaction in relation to the availability of social network was statistically significant, indicating that mothers are less satisfied with their social network including the spouse, some authors have highlighted the importance of the family environment and the psychological balance of parents in the medical and rehabilitation treatment of children ${ }^{[20,21]}$, knowing that in our study, family status (divorce or other status) is a risk factor for developing a state of stress twelve times a mother caring for a disabled child. Therefore parents need support and guidance to enable sharing emotional trauma of disability of the child. According to our study, the mother who is the weak link and is seven times more prone to suffer from high levels of perceived stress must require special attention. In our study, the socioeconomic level is a risk factor associated with perceived stress for parents of children and teenagers with $\mathrm{CP},{ }^{[15]} \mathrm{Z}$. Ben Salah and al., also found statistically significant relationships between the degree of social and financial gene and the psychological and mental state of the parents, in a study of a sample of forty-nine families (fathers and mothers of children with cerebral palsy. Our study shows, in multivariate analysis, the dependence of the child is not a factor associated with stress occurred, Verger et al have also confirmed that the type of disability and level of child dependency not influence the quality of life of the parents ${ }^{[19]}$. However, other studies have shown the opposite, that is the type of disorder impairs the family lived ${ }^{[22,23,24]}$.

\section{Conclusion}

This research demonstrates the suffering of parents with cerebral palsied children and adolescents and especially mothers with a high level of stress and dissatisfaction of the availability of social network. It also appears that the factors associated with perceived parental stress are related to gender (Female), marital status (divorce) and the socio-economic level (Low). This should encourage us to find the solutions helping families to overcome this deteriorated experience and break their isolation to reduce their stress and improve their conjugal balance. Finally, this research has some limitations. If our data have clarified in part the reality of parents, they do not allow us to have a perfect knowledge of the limits of statistical possibilities and results generalization ability, to the extent that the sample size is small and the comparison group is absent In the end a similar research would be interesting if it would cover a wider range in order to extrapolate results and develop a coping strategy of adaptation and support.

\section{Acknowledgements \& Conflicts Of Interest}

We thank the children's parents, children and teenagers for their participation. We also thank director and occupational therapists working in the centers of rehabilitation for their assistance with data collection; the project would not have been possible without their contributions. Present study is self funded by author \& her institution, no conflict of interest. 


\section{References}

[1]. Bax m, Goldstein m, Rosenbaum p. Proposed definition and classification of cerebral palsy. Dev Med Child Neurol 2005; 47 (8); $571-6$

[2]. Walker, L.S., Ford, M.B., \& Donald, W.D. (1987). Cystic Fibrosis and Family Stress: Effects of Age and Severity of Illness. Pediatrics, 79(2), 239-246.

[3]. Bruno Quintard, “le concept de stress et ses méthodes d'évaluation,'Recherche en soins infirmiers N 67 - décembre 2001

[4]. Cohen, S., Kamarck, T., \& Mermelstein, R. « A global measure of perceived stress ». Journal of Health and Social Behavior, 24(4), 386-396, 1983.

[5]. Bruchon-Schweitzer M., Bruchon-Schweitzer M., Quintard B. Personnalité et maladies.Stress,copingajustement.Ed.Dubod:Paris. [Online] Available:(http://www.invs.sante.fr/publications/2005/epidemiologie_catastrophes/module7.pdf), 2001. (accessed 12.11.14)

[6]. Wintgens A, Hayez JY. « Guidance psychopédagogique des parents d'enfants atteints d'autisme ». Psychiatr Enfant;49(1):207-26, 2006.

[7]. Baghdadli, A., Beuzon, S., Bursztjen, C., Constant, J., Desguerre, I., Rogé, B., Squillante, M., Voisin, J. et Aussilloux, C. In B. Rogé, C. Barthélémy et G. Magerotte (dir.), « Améliorer la qualité de vie des personnes autistes » (p. 193-211). Paris : Dunod, 2008.

[8]. Cappe E., Marion Wolff, René Bobet, Jean-Louis Adrien « étude de la qualité de vie et des processus d'ajustement des parents d'un enfant ayant un trouble autistique ou un syndrome d'Asperger : effet de plusieurs variables sociobiographiques parentales et caractéristiques liées à l'enfant ».Evolpsychiatr; 77(2), 2012.

[9]. Mouilly M, Faiz N, Ahami AOT, Abousalah Y « Qualité de vie des parents d'enfants et adolescents souffrants d'infirmité motrice cérébrale ». International Journal of Innovation and Applied Studies ISSN 2028-9324 Vol. 9 No. 4 Dec., pp. 1700-1707, 2014

[10]. Quittner, A. L. ,Digirolamo, A., Michel, M. et Eigen,H. « Parental Response to cystic fibrose : A contextual analysis in the diagnosis phase »,.Journal of pédiatrique psychology, 17(6),683-704, 1992.

[11]. Sen E, Yurtsever S. Difficulties experienced by families with disabled children. J Spec Pediatr Nurs 2007;12:238-52.

[12]. Brazier JE, Roberts J. The estimation of a preference-based measure of health from the SF-12. Med Care 2004;42:851-9.

[13]. Magill-Evans J, Darrah J, Pain K, Adkins R, Kratochvil M. Are families with adolescents and young adults with cerebral palsy the same as other families? Dev Med Child Neurol 2001;43: 466-72.

[14]. White-Koning M, Arnaud C, Dickinson HO, Thyen U, Beckung E, Fauconnier J, et al. Determinants of child-parent agreement in quality-of-life reports: a European study of children with cerebral palsy. Pediatrics 2007;120:e804-14.

[15]. Z. Ben Salah Friha, S. Boudoukhanea, A. Jellada, S. Salaha, N. Rejeb Qualité de vie des parents d'enfant atteint de paralysie cérébrale Journal de réadaptation médicale 2010;30:18-24

[16]. Hilbert G, Gail A, Walker M, Rinehart J. "In for the long haul”: Responses of parents caring for children with Sturge-Weber syndrome. J Fam Nurs 2000;6:157-80.

[17]. Elliot B, Luker K. The experiences of mothers caring for a child with severe atopic eczema. J Clin Nurs 1997;6:241-7.

[18]. Whiteneck GG, Charlifue SW, Gerhart KA, Overhosler JD, Richardson G. quantifying handicap: a new measure of long term rehabilitation outcomes. Arch Phys Rehabil 1992;73:519-25.

[19]. Verger S, Nicolas B, Pialoux B, Branger B, Brissot R. enque`te sur le retentissement familial du handicap de l'enfant. Intérêts de la MIF-Môme. Ann Readapt Med Phys 1999;42:323-32.

[20]. Taanila A, Kokkonen J, Jarvelin MR. the long-term effects of chlidren's early-onset disability on marital relationships. Dev Med Child Neurol 1996;38:567-77.

[21]. Nuutila L, Salanter S. Children with a long-term illness: parents' experiences of care. J Pediatr Nurs 2006;21:153-60.

[22]. Beckman PJ. Comparisons of mother's and father's perceptions of the effects of young children with and without disabilities. Am J Ment Retard 1995;95:585-95.

[23]. Pless IB, Satterwithe B. A measure of family functioning and its application. Soc Sci Med 1973;7:613-21.

[24]. Jessop DJ, Riessman CK, Stein REK. Chronic childhood illness and maternal health. Dev Behav Pediatr 1988;9:147 56. 